\title{
Assessment of the potential of dimethyl ether as an alternative fuel for compression ignition engines
}

\begin{abstract}
The main problem that the automotive industry has been dealing with since the beginning of the XXI century is the need to reduce the exhaust emissions from piston combustion engines. Another, not at all less important problem is the depleting natural resources of crude oil. There are many concepts aiming at resolving of the said issues. One of them is the possibility of application of dimethyl ether (DME) in a classic engine. The paper characterizes this fuel, drawing attention to the aspects related to the adaptation of the engine to this type of fuel, presents the process of its atomization and relevant exhaust emissions.
\end{abstract}

Key words: dimethyl ether, DME, alternative fuels, common rail, biofuel

\section{Introduction}

The automotive sector is one of the branches of economy whose dynamics of advancement is tightly related to the development of industry. A constant increase in the widely understood production results in a need to transport a greater amount of raw materials and ready made products therefore, the advancement of transport boosts the advancement of industry. The greatest dynamics in the growth of the number of vehicles in recent years has been observed in rapidly developing countries such as China or India (Fig. 1). It is forecasted that within the next 20 years, the number of vehicles worldwide will double.

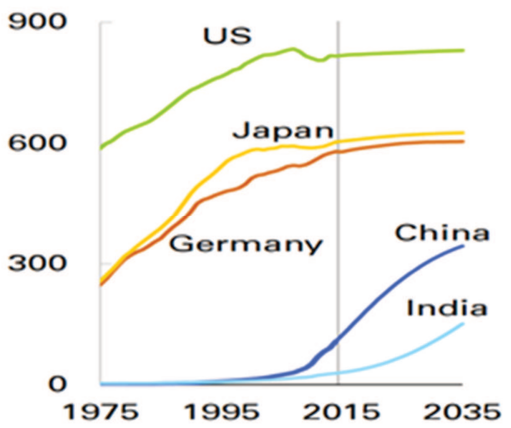

Fig. 1. Number of vehicles per 1000 inhabitants in individual regions of the world [2]

Energy plays an important role in the discussed problems. In order to preserve the dynamics of the advancement of the automotive industry, it is necessary to provide proper quantity of the said energy. In the automotive sector, the energy used to propel vehicles comes from the fuel - mainly the product of distillation of crude oil. It is widely known that the world resources of fossil fuels such as crude oil coal or natural gas will eventually deplete. In order to provide sufficient amount of fuel guaranteeing an unrestrained advancement of the automotive industry, it is necessary to diversify the fuel resources. Therefore, greater emphasis has been put on the search for alternative sources of energy. Renewable fuels such as fatty acid methyl esters (FAME) are gaining in popularity. They are a product of estrification of oil obtained from rapeseed. This fuel is characterized by good energy related properties (the calorific value of this fuel is close to that of diesel fuel). This fuel however, has slightly different density and viscosity, which makes it difficult to apply in modern injection systems. Additionally, due to food deficit in some regions of the world, production of fuels from materials that can be used to manufacture food is reduced. This opens a window of opportunity for entirely new fuels referred to as second generation alternative fuels, dimethyl ether - DME being one of them.

\section{Characteristics of dimethyl ether as a fuel}

Dimethyl ether is an odorless and colorless organic compound belonging to the group of ethers. Under typical ambient conditions (pressure $0.1 \mathrm{MPa}$ and temperature $25^{\circ} \mathrm{C}$ ) it remains in the volatile phase. In a closed space under pressure of its own vapor it changes into liquid. Selected properties of DME and their comparison with diesel fuel and FAME have been shown in Table 1.

The density of volatile dimethyl ether is greater than that of air. In its liquid phase, it is approx. $80 \%$ of the density of diesel fuel and only $72 \%$ of the density of FAME. Given this parameter, in order to supply the same mass of fuel, it is necessary to provide $20 \%$ more volume of DME compared to conventional fuel and $25 \%$ more compared to FAME. Dimethyl ether is sparingly soluble in water. Its maximum mass share in the mixture does not exceed $6 \%$. Carbon has the greatest mass share of $52.2 \%$ in a DME molecule. The share of hydrogen in the molecule mass is estimated at $13 \%$. It is noteworthy that DME has better carbon to hydrogen ratio than diesel fuel $(\mathrm{C} / \mathrm{H})$. This results in a lesser amount of $\mathrm{CO}_{2}$ and greater amount of $\mathrm{H}_{2} \mathrm{O}$ generated following full combustion, which is the effect of the combustion of hydrogen. A DME molecule does not have direct bonds among the atoms of carbon - this facilitates full combustion, thus reducing the amount of carbon monoxide and particulate matter. Full combustion is also facilitated by a reduction of local oxygen deficits through the presence of this element in the molecule. Oxygen constitutes $34.8 \%$ of the molecule mass, which makes the calorific value of DME $40 \%$ lower compared to other fuels. Given the density and calorific value of other fuels, there is 18409 
MJ of energy stored in $1 \mathrm{~m}^{3}$ of liquid dimethyl, $35317 \mathrm{MJ}$ of energy in $1 \mathrm{~m}^{3}$ of diesel fuel and $36312 \mathrm{MJ}$ in $1 \mathrm{~m}^{3}$ of FAME. In order to supply the same amount of energy, it is necessary to provide almost twice the volume of DME.

Due to the presence of the atom of oxygen, the stoichiometric air fuel ratio necessary for a full and complete combustion is also different. For the analyzed alternative fuel, this ratio is 9 . It means that in order for the full combustion of $1 \mathrm{~kg}$ of dimethyl ether to take place, one needs only $9 \mathrm{~kg}$ of air. This amount is lower than that of diesel fuel, for which the mass of air needed for full combustion is $14.6 \mathrm{~kg}$.

Table 1. Comparison of the properties of dimethyl ether with diesel fuel and fatty acid methyl esters FAME [1, 5, 15, 18]

\begin{tabular}{|l|c|c|c|c|}
\hline Properties & Unit & $\begin{array}{c}\text { Diesel } \\
\text { fuel }\end{array}$ & $\begin{array}{c}\text { Dimethyl } \\
\text { ether } \\
\text { DME }\end{array}$ & $\begin{array}{c}\text { Methyl } \\
\text { esters } \\
\text { FAME }\end{array}$ \\
\hline Critical pressure & {$[\mathrm{MPa}]$} & 3.00 & 5.37 & 8.1 \\
\hline Lower heating value & {$[\mathrm{MJ} / \mathrm{kg}]$} & 42.5 & 27.6 & 39.5 \\
\hline Lower explosive limit & {$[\% \mathrm{vol}]$.} & 0.6 & 3.2 & - \\
\hline Fluid density & {$\left[\mathrm{kg} / \mathrm{m}^{3}\right]$} & 831 & 667 & 919.3 \\
\hline Upper explosive limit & {$[\% \mathrm{vol}]$.} & 7 & 18 & - \\
\hline Fluid kinematic viscosity & {$[\mathrm{cSt}]$} & 3 & $<0.1$ & 38 \\
\hline Cetane number & & $40-50$ & 58 & $54-56$ \\
\hline Mole mass & {$[\mathrm{g} / \mathrm{mol}]$} & 170 & 46 & 296 \\
\hline Surface tension & {$[\mathrm{N} / \mathrm{m}]$} & 0.027 & 0.012 & 0.352 \\
\hline Vapor pressure & {$[\mathrm{kPa}]$} & $<<10$ & 530 & 0.42 \\
\hline C/H ratio & & 6.14 & 4.01 & 6.41 \\
\hline $\begin{array}{l}\text { Stoichiometric air fuel } \\
\text { ratio }\end{array}$ & & 14.6 & 9 & 12.5 \\
\hline Chemical structure & ${ }^{\circ} \mathrm{C}$ & 434 & 126 & 239 \\
\hline Critical temperature & ${ }^{\circ} \mathrm{C}$ & 249 & 234 & 261 \\
\hline Self ignition temperature & $176-370$ & -25 & $280-350$ \\
\hline $\begin{array}{l}\text { Boiling temperature at } \\
\text { latm }\end{array}$ & {$[\% \mathrm{mass}]$} & 14 & 13 & 12 \\
\hline Oxygen content & & - & $\mathrm{CH}_{3}-\mathrm{O}-\mathrm{CH}_{3}$ & - \\
\hline Carbon content & & 0 & 34.8 & 1 \\
\hline Hydrogen content & & 52.2 & 77 \\
\hline
\end{tabular}

\section{Engine adaptation for dimethyl ether fueling}

The fueling of a diesel engine with dimethyl ether is possible without any substantial modifications. Yet, due to its low boiling temperature of $-25^{\circ} \mathrm{C}$, it is necessary to store ether in an airtight container. The pressure generated by its vapor converts ether into a liquid under temperatures of 20 $-30^{\circ} \mathrm{C}$ (Fig. 2), which allows the application of the already existing LPG solutions for its storage (fuel tank) [10].

In the case of diesel engines used as power generators and pumps, the adaptation to DME fueling can be much easier. These engines operate under steady state conditions - constant engine speed and load, which allows the application of components from the second generation LPG systems - a pressure reducer and a mixer (or gas carburetor). The schematics of such a solution has been shown in Fig. 3. The application of such a simple system is possible thanks to the properties of DME. Low boiling temperature of dimethyl ether results in the fuel evaporating quickly and forming a homogenous mixture with air and its high cetane number and a relatively low self-ignition temperature facilitate the mixture ignition and the proper course of the combustion process.

Because it is impossible to precisely control the fuel dosage, the above solution is good only for engines operating under steady state conditions. As for the engines used in vehicles, in order to meet the required exhaust emission standards and ensure sufficient operating parameters, it is necessary to adapt the existing fuel systems to a fuel of different properties.

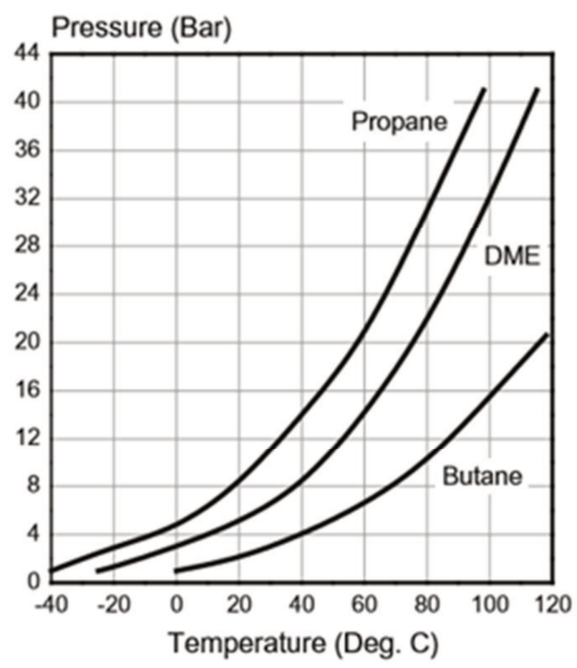

Fig. 2. Comparison of the vapor pressure of dimethyl ether and propane and butane [4]

The most commonplace fuel system in modern diesel engines is the common rail injection system. The application of an alternative fuel forces its supply in the liquid phase to the high pressure pump. Therefore, in the case of DME, it is necessary to use an additional pump sucking the liquid fuel from the tank - this allows the liquid phase to be pumped to the common rail high-pressure pump.

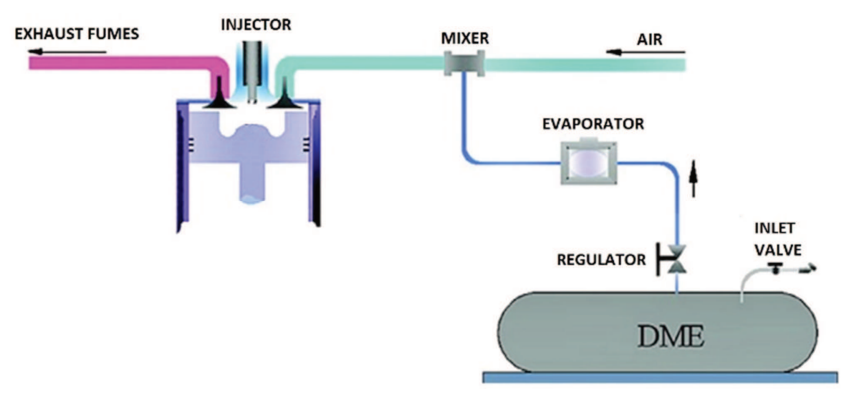

Fig. 3. Schematics of the system for the adaptation of a diesel engine to dimethyl ether fueling [6]

When applying dimethyl ether in modern fuel systems of diesel engines, one should remember that this compound is also a very good solvent and may have an adverse effect on the durability of the elastomer seals. When adapting the engine to DME fueling, it should, thus, be checked whether the seals in the system are DME proof. The application of 
an alternative fuel of low viscosity, density and lubricity in a fuel system may result in unknown operating issues related to premature wear. Low values of viscosity and density result in more fuel passing through leakages in the pumping section or the control valves of the high-pressure pump, which is why, in order to perform the same work, greater flow is required. The greatest impact of the reduced density and viscosity is observed inside the injector where any leakage may result in a loss of control on the engine operation (fuel ingress into the combustion chamber).

In terms of the operational aspects, a significant problem is the DME's low lubricity, which may lead to premature wear of the surface layers of the mating components, which, in turn, may lead to increased leakage and, in extreme cases, damage the high pressure pump and the injectors. The problem of lubricity may be relatively easily resolved by the application of appropriate fuel additives.

\section{DME atomization characteristics}

Because of its low boiling temperature, dimethyl ether injected into the combustion chamber evaporates immediately forming a homogenous mixture with air. Research on the injection and atomization of dimethyl ether have been conducted by many research groups. Wakai et al. [17] have performed tests based on the Schlieren optical system. During the experiment, the alternative fuel was injected with a standard injector into the combustion chamber under the pressure of 1-15 bar. Sorenson et al. [14] have described the phenomena taking place during high-pressure injection of liquid DME with a lubricating additive.

During the injection of dimethyl ether into the combustion chamber, in which the pressure is lower than that of vapor saturation, the DME evaporates immediately. The penetration of the fuel spray front is close to conventional fuel, but the angle of the cone bifurcation and its volume are greater. The main reason for improved atomization is the occurrence of abrupt evaporation of oversaturated vapors. The boundary of the injected fuel spray of DME appears to be less regular compared to conventional fuel. The irregularity of the contour increases with the cylinder pressure [17].

As of the moment when the pressure of the dimethyl ether droplets reaches the supercritical area, the atomization becomes turbulent, which facilitates its good mixing with air. The atomization process may be turbulent as the fuel spray develops. If the fuel droplets are sufficiently small, their evaporation may take place already in the injection nozzle, which will affect further atomization stages. Wakai et al. [17] suggest that in areas of low pressure in the atomizer channels, cavitation may occur more easily compared with diesel fuel. It has also been confirmed that the mechanism of cavitation in the system may boost the atomization in the fuel spray, thus positively affecting the atomization of dimethyl ether. Other authors [7] suggest that the occurrence of gas-liquid flow of injected fuel significantly affects the bifurcation of the fuel spray cone. They, however, do not confirm the positive effect of cavitation on the process of fuel atomization. The comparison of atomization of dimethyl ether and diesel fuel under actual conditions of operation has shown that for high loads and engine speeds, the DME spray penetration is smaller compared with diesel fuel. This happens because of the longer duration of the injection and an increase in the angle of the fuel spray cone resulting from the high gaseous to liquid phase ratio in the injected spray. The analysis of dimethyl ether atomization shows that in order to obtain better mixing quality and better fuel combustion, a modification of the shape of the combustion chamber is recommended. The comparison of the atomization of dimethyl ether and diesel fuel has been shown in Fig. 4.

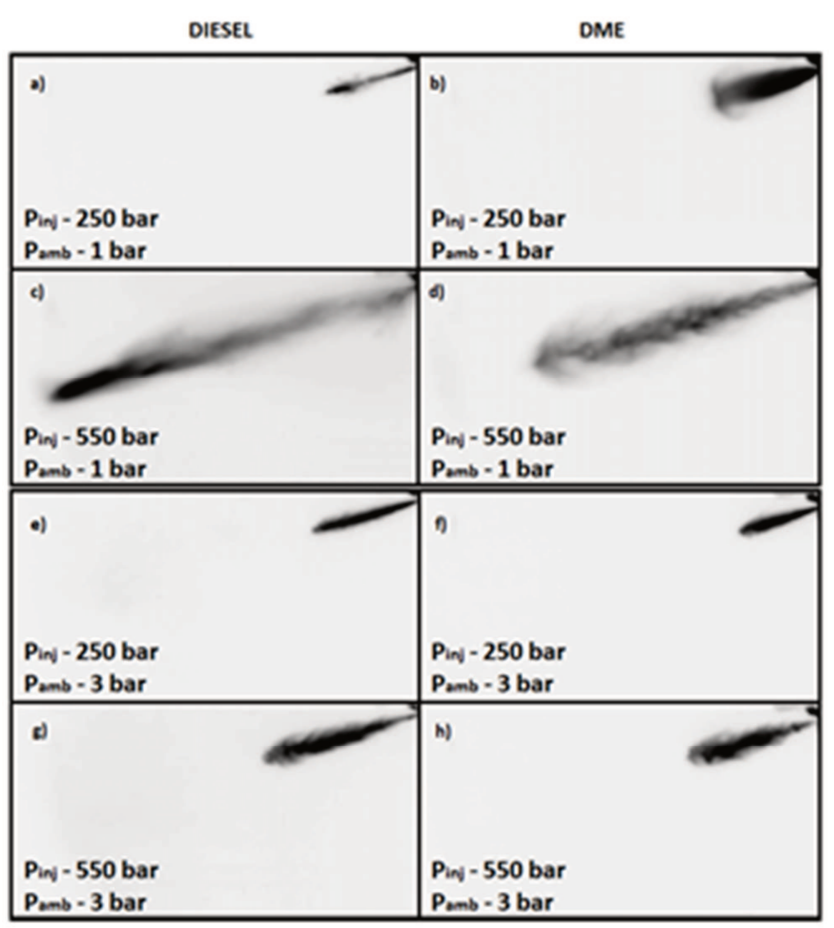

Fig. 4. Comparison of the atomization of DME and diesel fuel under different injection conditions [16]

\section{Characteristics of DME emissions}

Majority of published research results on exhaust emissions from diesel engines fueled with dimethyl ether indicates a significantly better emission performance compared to diesel fuel. Scarce emission of PM observed during DME combustion is most likely the result of combustion of the lubricating oil or the fuel lubricants. The reduced emission of particulate matter is mainly a result of the low boiling temperature that causes better evaporation of the fuel and its better mixing with air, simple composition of the molecule, presence of oxygen in the molecule and no direct bonds between the atoms of carbon. The comparison of smoke opacity tests performed on an engine fueled with different fuels has been shown in Fig. 5. Fig. 6 presents the results of particulate mass (PM) and particulate number (PN) tests performed on a diesel engine fueled with diesel fuel and DME. It is noteworthy that, in terms of mass, the engine fueled with DME generates much less particulate matter compared with diesel fuel but in terms of number the differences for both fuels are smaller and depend on the engine speed.

Numerous research in exhaust emissions performed by world renowned experts do not lead to clear conclusions as to the emission of $\mathrm{NO}_{\mathrm{x}}$. Part of the publication presents information that the share of this component in the exhaust gas during combustion of dimethyl ether is lower than that 
of diesel fuel $[3,9,21]$. The reduction of the $\mathrm{NO}_{\mathrm{x}}$ emission is said to result from the fact that DME has lower calorific value, higher cetane number and greater thermal capacity compared to diesel fuel. These characteristics reduce the ignition delay time, which results in a smaller amount of burnt fuel remains in the chamber, thus giving an effect similar to EGR [12].

Some of the scientists $[2,8]$ think that the short time of ignition delay and almost perfect evaporation of the alternative fuel adds to the rapid pressure and temperature increase during combustion, which facilitates the formation of nitrogen oxides. The positive effect of the operation of EGR has also been confirmed with numerous investigations. EGR much better inhibits $\mathrm{NO}_{\mathrm{x}}$ formation when the engine is fueled with DME and does not increase the emission of PM (no need to apply SCR) [13].
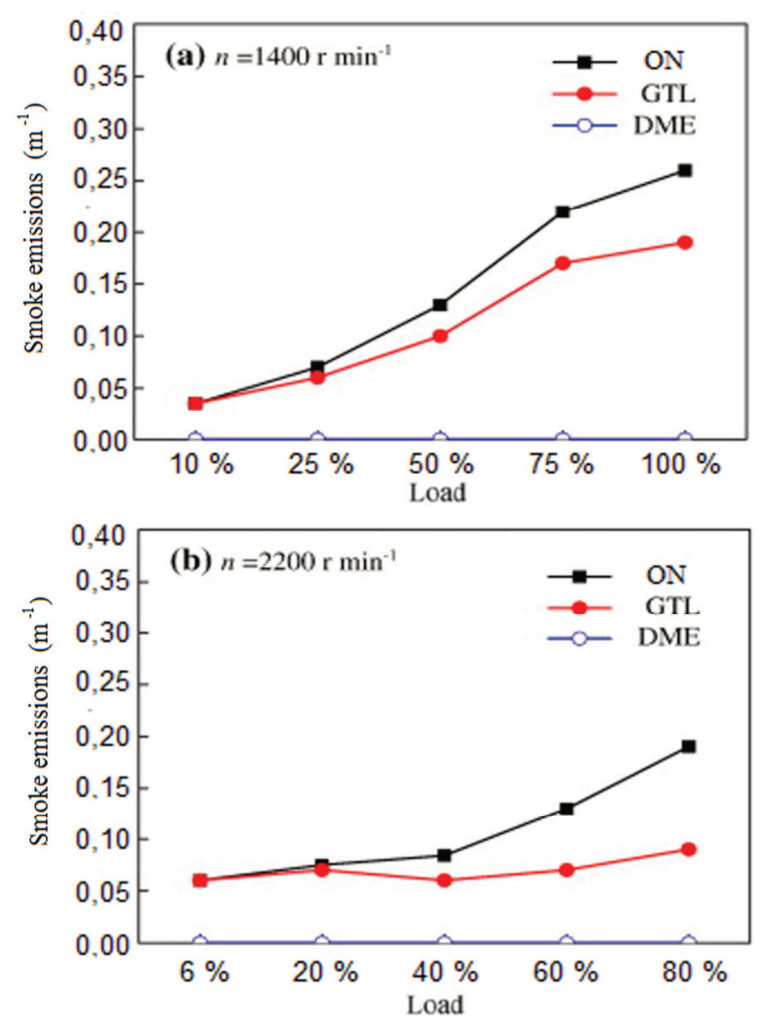

Fig. 5. Comparison of the smoke opacity when fueled with diesel fuel, GasToLiquid and DME under different conditions of engine operation [19]

The investigations of the exhaust emissions conducted by Youn et al. [20] have shown that the quantity distribution of the generated hydrocarbons depends on the moment of fuel injection into the combustion chamber. An increase in the injection delay results in greater HC emission (Fig. 7a). This relation is particularly conspicuous for higher engine speeds. Compared to diesel fuel, the combustion of dimethyl ether in a compression ignition engine is characterized by a lower emission of hydrocarbons for the entire range of injection time. An increased emission is visible only for very delayed injection and higher engine speeds. The main reason for such a low emission of $\mathrm{HC}$ is the composition of the molecule, the presence of oxygen as well as rapid and full evaporation of the injected fuel. This also pertains to residual fuel in the injector, constituting one of the main reasons for excess HC emission - increased evaporation rate allows better mixing of the fuel with air and facilitates full combustion.
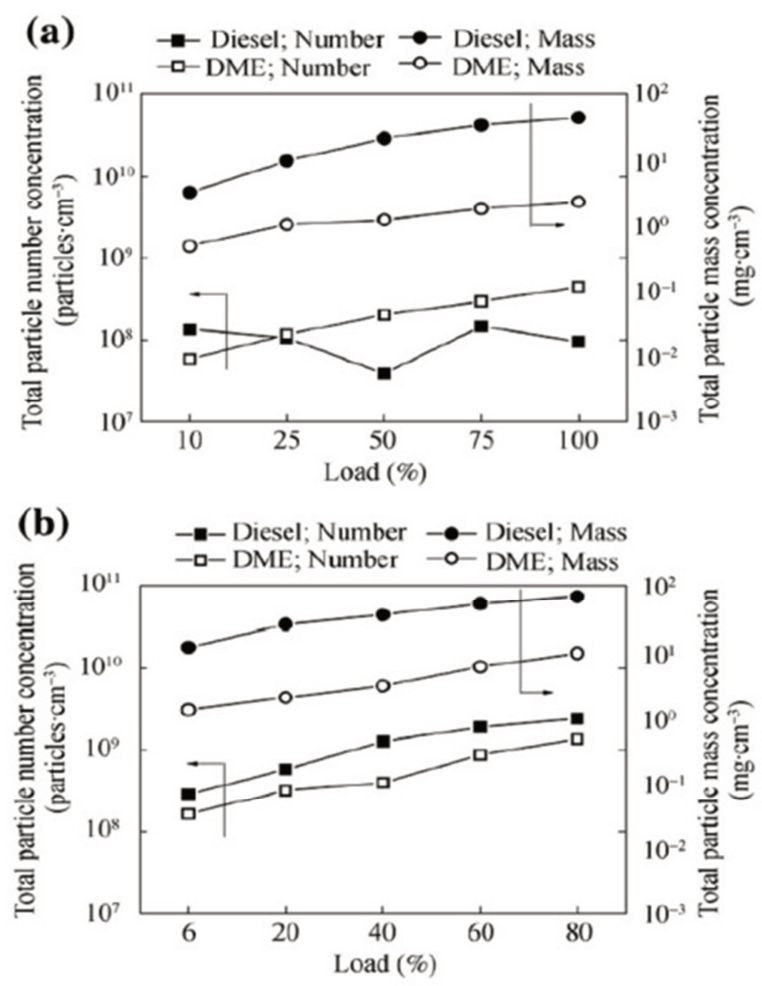

Fig. 6. The influence of the engine load and speed on the exhaust particle number and mass concentration for DME and diesel fueled engines; (a) $1400 \mathrm{rpm}$, (b) $2200 \mathrm{rpm}$

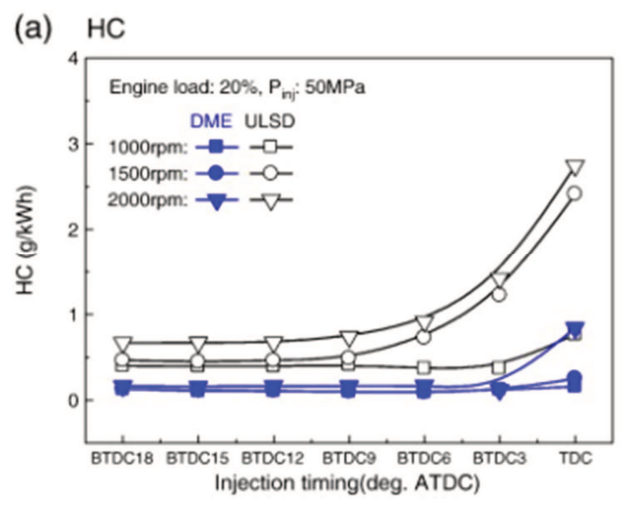

(b) $\mathrm{CO}$

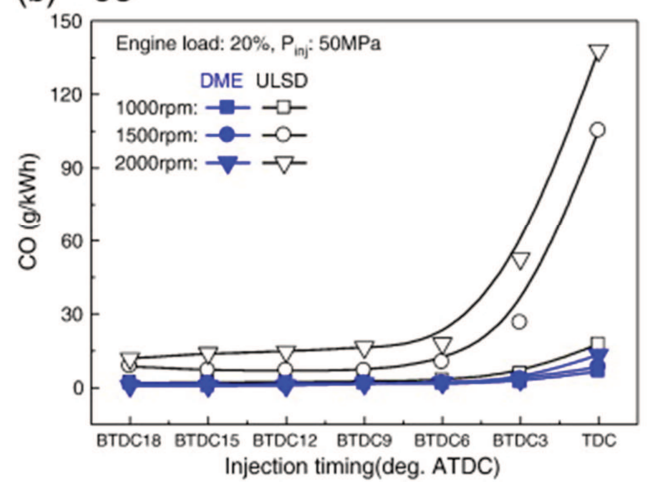

Fig. 7. Comparison of the emission of $\mathrm{HC}$ and $\mathrm{CO}$ for combustion of DME and diesel fuel [20] 
Figure $7 \mathrm{~b}$ presents the results of measurements of the emission of carbon monoxide. Similarly to the emission of $\mathrm{HC}$, the emission of $\mathrm{CO}$ for dimethyl ether, turned out lower compared to diesel fuel. Only a slight increase has been observed for high engine speeds and late fuel injection. In the case of conventional fuel, an increase in the emission of $\mathrm{CO}$ under the said conditions is much more conspicuous. The formation of carbon monoxide is mainly attributed to local oxygen deficits and the occurrence of incomplete combustion. The amount of generated carbon monoxide during the combustion of DME is influenced by the presence of the atom of oxygen in the molecule, which reduces the amount of air necessary for full combustion.

\section{Conclusions}

Thanks to its chemical properties such as high cetane number, low boiling and ignition temperatures, dimethyl ether turns out to be a very good fuel for compression ignition engines. Dimethyl ether mixes with air well and is easily ignited even under sub zero temperatures. Its lower density, viscosity and lubricity compared to conventional fuels are potential downsides but may be cost-effectively eliminated by adapting of the injection systems and introducing fuel lubricity additives.

The potential of DME application in compression ignition engines has its environment related implications. Di- methyl ether has a very good carbon to hydrogen ratio, which generates more water vapor during combustion. Through no direct bond between the carbon atoms, formation of particulate matter is limited so that high exhaust gas recirculation rate is possible in order to reduce $\mathrm{NO}_{\mathrm{x}}$, which renders the application of any additional aftertreatment systems unnecessary. Because of good evaporation rate and the presence of oxygen atom in the molecule, the emission of carbon monoxide and hydrocarbons is also reduced, compared to diesel fuel. Besides, the adverse ecological impact of this fuel is reduced by a good $\mathrm{CO}_{2}$ balance - DME may be manufactured from renewable materials such as wood chips, biomass or waste. Other than exhaust emissions the DME's environmental characteristics also include: no toxic, carcinogenic, teratogenic and mutagenic impact on the living organisms, safe decay products (water and carbon dioxide), short half-life in the troposphere and no impact on the stratosphere.

Proper adaptation of the infrastructure consisting in partial adapting of the existing solutions used in the LPG distribution may result in this fuel becoming increasingly popular and the group comprising Sweden, Denmark, USA, Japan, Korea and China, where DME road tests are in progress, will eventually expand.

LPG liquified petroleum gas

SI spark ignition

$$
\begin{array}{ll}
\text { CI } & \text { compression ignition } \\
\text { CNG } & \text { compressed natural gas } \\
\text { DI } & \text { direct injection }
\end{array}
$$

\section{Bibliography}

[1] ALAM, M., FUJITA, O., ITO, K. et al. Performance of $\mathrm{NO}_{\mathrm{x}}$ catalyst in a DI diesel engine operated with neat dimethyl ether. SAE Technical Paper. 1999, 1999-01-3599.

[2] BP Energy Outlook 2016 Edition www.bp.com/energyoutlook (accessed 10.05.2016).

[3] EGNELL, R. Comparison of heat release and $\mathrm{NO}_{\mathrm{x}}$ formation in a DI diesel engine running on DME and diesel fuel. SAE Technical Paper. 2001, 2001-01-0651.

[4] FLEISCH, T., MCCARTHY, C., BASU, A. et al. A new clean diesel technology: demonstration of ULEV emissions on a Navistar diesel engine fueled with dimethyl ether. $S A E$ Technical Paper. 1995. 950061.

[5] HUANG, Z.H., WANG, H.W., CHEN, H.Y. et al. Study of combustion characteristics of a compression ignition engine fuelled with dimethyl ether. Proc Instn Mech Engrs. 1999, 213, D, 647-52.

[6] JUNJUN, Z., XINQI, Q., ZHEN, W. et al. Experimental investigation of low-temperature combustion (LTC) in an engine fuelled with dimethyl ether (DME). Energy \& Fuels. 23, 2009.

[7] KAPUS, P., OFNER, H. Development of fuel injection equipment and combustion system for DI diesels operated on di-methyl ether. SAE Trans J Fuel Lubr. 1995, 104(4), 54-59, 950062 .

[8] KIM, M.Y., YOON, S.H., RYU, B.W., LEE, C.S. Combustion and emission characteristics of DME as an alternative fuel for compression ignition engines with a high pressure injection system. Fuel. 2008, 87, 2779-2786.
[9] KONNO, M., KAJITANI, S., OGUMA, M. et al. NO emission characteristics of a CI engine fueled with neat dimethyl ether. SAE Technical Paper. 1999, 1999-01-1116.

[10] OWEN, K., COLEY, T., WEAVER, C.S. Automotive fuels reference book. 2nd ed. SAE International Inc. 1995.

[11] PARK, S.H., LEE, C.S. Applicability of dimethyl ether (DME) in a compression ignition engine as an alternative fuel. Energy Conversion and Management. 2014, 86, 848863.

[12] PARK, S.H., LEE, C.S. Combustion performance and emission reduction characteristics of automotive DME engine system. Progress in Energy and Combustion Science. 2013, 39, 147-168.

[13] PARK, S.H., CHA, J., PARK, S., LEE, C.S. Simultaneous reduction in the exhaust emissions by a high exhaust gas recirculation ratio in a dimethyl-etherfuelled diesel engine at a low-load operating condition. Proc Inst Mech Eng D J Aut. 2012, 226(8), 1130-1142.

[14] SORENSON, S.C., GLENSVIG, M., ABATA, D. Di-metyl ether in diesel fuel injection systems. SAE Trans $J$ Fuel Lubr. 1998, 107(4), 438-449, 981159.

[15] SORENSON, S.C., MIKKELSEN, S.-E. Performance and Emissions of a 2.3 Liter Direct Injection Diesel Engine Fuelled with Neat Dimethyl Ether. SAE Technical Paper. 1995, 950064.

[16] TSUCHIYA, T., SATO, Y. Development of DME engine for heavy-duty truck. SAE Technical Paper. 2006, 200601-0052.

[17] WAKAI, K., NISHIDA, K., YOSHIZAKI, T., HIROYA$\mathrm{SU}, \mathrm{H}$. Spray and ignition characteristics of di-methyl ether 
injected by a DI diesel injector. Proceedings of the fourth international symposium COMODIA'98. 1998, 537-542.

[18] WANG, H.W., ZHOU, L.B. Performance of direct injection diesel engine fueled with DME/diesel blend. Fuel, Better Air Quality in Asian and Pacific Rim Cities (BAQ 2002), 2002.

[19] XINLING, L., ZHEN, H. Emission reduction potential of using gas-to-liquid and dimethyl ether fuels on a turbocharged diesel engine. Science of The Total Environment. 2009.

[20] YOUN, I.M., PARK, S.H., ROH, H.G., LEE, C.S. Investigation on the fuel spray and emission reduction characteris-

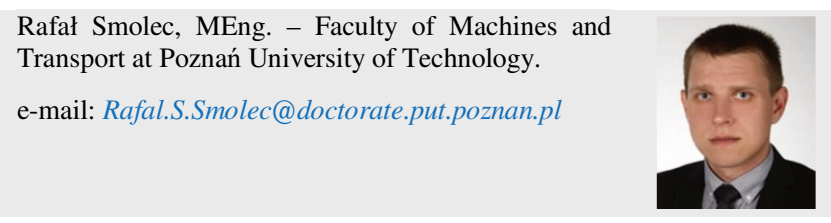

Prof. Marek Idzior, DSc., DEng. - Faculty of Machines and Transport at Poznań University of Technology.

e-mail: Marek.Idzior@put.poznan.pl tics for dimethyl ether (DME) fueled multi-cylinder diesel engine with common-rail injection system. Fuel Processing Technology. 2011, 92(7), 1280-1287.

[21] FLEISCH, T.H., MEURER, P.C. DME - the diesel fuel for the 21st century?. AVL Conference Engine and Environmental 1995. Graz, Austria.

[22] THOMAS, G., FENG, B., VEERARAGAVAN, A. et al. Emissions from DME combustion in diesel engines and their implications on meeting future emission norms - a review. Fuel Processing Technology. 2014, 119, 286-304.
Wojciech Karpiuk, DEng. - Faculty of Machines and Transport at Poznań University of Technology.

e-mail: Wojciech.Karpiuk@put.poznan.pl

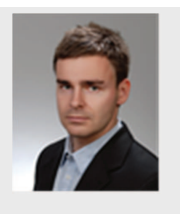

Miłosław Kozak, DSc., DEng. - Faculty of Machines and Transport at Poznań University of Technology.

e-mail: Miloslaw.Kozak@put.poznan.pl

\section{LIDER}

This publication has been written within the project 'New generation of common rail injection pumps' in Lider V (Lider/015/273/L-5/13/NCBR/2014), financed by National Research and Development Centre. 